
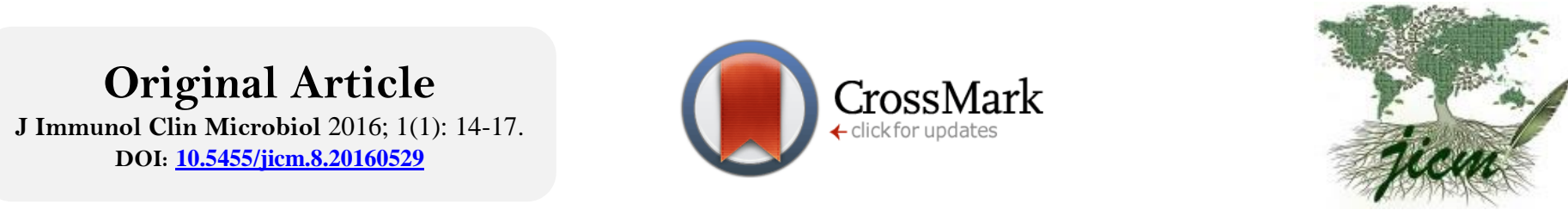

J Immunol Clin Microbiol

\title{
Investigation of liver autoantibodies in anticentromere antibody positive patients: A preliminary research
}

\author{
Asli Gamze Sener ${ }^{1 *}$, Celal Bugdaci ${ }^{1}$, Erkan Yula ${ }^{1}$, Ilhan Afsar ${ }^{1}$, Emine Figen Tarhan $^{2}$, Selcuk Kaya ${ }^{1}$ \\ ${ }^{1}$ Izmir Katip Celebi University, Ataturk Training and Research Hospital, Medical Microbiology Laboratory. Izmir, Turkey. \\ ${ }^{2}$ Izmir Katip Celebi University, Ataturk Training and Research Hospital, Rheumatology Department, Izmir, Turkey.
}

\begin{abstract}
Background: Anticentromere antibody (ACA) is regarded to be a serological marker specific to CREST (calcinosis, Raynaud's phenomenon, esophageal dysmotility, sclerodactylia, and telangiectasia) syndrome. ACA is also found in the sera of patients with autoimmune liver disease. In the present work, anti-soluble liver antigen \liver pancreas antigen (anti-SLA \LP), anti-liver cytosolic antigen 1 (anti-LC1), anti-liver kidney microsomal antigen 1 (anti-LKM1), and antimitochondrial antibody M2 (AMA-M2) were evaluated in the patients who had positive anticentromere antibody.

Material and Methods: A total of 39 patients who were positive anticentromere antibody were enrolled in this study undertaken in the Izmir Katip Celebi University, Ataturk Training and Research Hospital, Microbiology laboratory between January and September 2015. Positive anticentromere antibody and liver autoantibodies were analyzed. Anticentromere antibody and liver autoantibodies were studied by indirect immunofluorescence method (IIF) and immunoblotting method (IB), respectively. The patients who had negative anticentromere antibody were used as a control group.

Results: According to the study's results, positivity was detected in 3 of 39 patients (\%7.6) in terms of liver autoantibodies, all of which were AMA-M2. There was no statistically significant difference between ACA and autoimmune liver autoantibodies.

Conclusion: In this study, we reported our preliminary experience to provide evidence for the detection of various autoantibodies as potential diagnostic or prognostic tests. Further studies that contain a broad range of patients may contribute to the field.
\end{abstract}

Key words: Anticentromere antibody, autoimmune hepatitis, immunofluorescence method.

\section{Introduction}

$\boldsymbol{A}$ nticentromere antibody (ACA) is regarded to be a serological marker specific to CREST (calcinosis, Raynaud's phenomenon, esophageal dysmotility, sclerodactylia, and telangiectasia) syndrome (1-4). In addition to being present in CREST syndrome, ACA is also detected in the sera of patients with autoimmune liver disease (5).
In the present study, anti-soluble liver antigenliver pancreas antigen (anti-SLALLP), anti-liver cytosolic antigen 1 (anti-LC1), anti-liver kidney microsomal antigen 1 (anti-LKM1), and anti-mitochondrial antibody M2 (AMA-M2) were evaluated in the patients who had positive anticentromere antibody.
*Corresponding Author: Asli Gamze Sener. Izmir Katip Celebi University, Ataturk Training and Research Hospital, Medical Microbiology Laboratory. Izmir, Turkey E-mail: agsener@gmail.com Received: Apr 12, 2016. Accepted: Apr 27, 2016 Published Online: May 30, 2016.
This is an Open Access article distributed under the terms of the Creative Commons Attribution Non-Commercial License (http://creativecommons.org/licenses/bync/4.0/) which permits unrestricted non-commercial use, distribution, and reproduction in any medium, provided the original work is properly cited. 


\section{Material and methods}

A total of 39 patients who had positive anticentromere antibody were enrolled in this study undertaken in the Izmir Katip Celebi University, Ataturk Training and Research Hospital, Microbiology laboratory between January and September 2015. The patients who had negative anticentromere antibody were used as a control group. Positive anticentromere antibody and liver autoantibodies were analyzed retrospectively. Anticentromere antibody and liver autoantibodies were studied by indirect immunofluorescence method (IIF) and immunoblotting method (IB), respectively. Blood samples were collected in serum separator tubes, centrifuged at 2,500 $\mathrm{rpm}$ for $10 \mathrm{~min}$. ANA patterns were evaluated by using the HEp-2010/Liver (Monkey) indirect immunofluorescence assay kit (Euroimmun AG, Lübeck, Germany, Lot No. F160318DI). Serum samples were processed in a dilution of 1:100 and conjugated with specific anti-human IgG (Euroimmune AG, Lübeck, Germany, Lot No. F160318DI). The fluorescence intensity was scored at x 400, semi-quantitatively from $1+$ to $4+$ relative to the intensity of the positive (4+) and negative control. The test result was discarded if the positive control sample failed to show the precise results. There has not been any duplication in assessing the samples. In immunoblotting method liver profile (Euroimmune AG, Lübeck, Germany, Lot No. D150327AD) that contains nylon strips coated with AMA M2, LKM-1, LC-1, SLA/LP antigens along with a control band was used (Figure1).

\section{Statistical analysis}

The difference between variables was analyzed by the statistical Chi square test. Statistical analyses were performed using SPSS version 22.0 for Windows (SPSS Inc., Chicago, IL, USA). A p-value $<0.05$ was considered to be significantly different.

\section{Results}

The patients ( 1 male and 38 females) were aged between 28 -80 years, an average of $56.7 \pm 11,4$ years. Among ACA-positive patients (Figure 2), 16 (41\%) systemic sclerosis (SSc), $12(30.8 \%)$ mixed connective tissue disease (MCTD) and 11 (28.2\%) CREST diagnoses were detected. AMA-M2 positivity was detected in 3 (7.6\%) of 39 ACA-positive patients (Table 1). All of the positive liver autoantibodies were AMA-M2 antibodies and all of the positive patients were women. There was no statistically significant difference between ACA and autoimmune liver autoantibodies ( $p>0.05)$.

Table 1. Diagnosis and the number of positive liver autoantibody results of the patients.

\begin{tabular}{lllll}
\hline & $\begin{array}{l}\text { AMA- } \\
\text { M2 }\end{array}$ & LKM-1 & SLA/LP & LC-1 \\
\hline CREST & 2 & 0 & 0 & 0 \\
$\begin{array}{l}\text { syndrome } \\
\text { Systemic }\end{array}$ & 0 & 0 & 0 & 0 \\
sclerosis & & & & \\
MCTD & 1 & 0 & 0 & 0 \\
Total & $\mathbf{3}$ & $\mathbf{0}$ & $\mathbf{0}$ & $\mathbf{0}$ \\
\hline
\end{tabular}

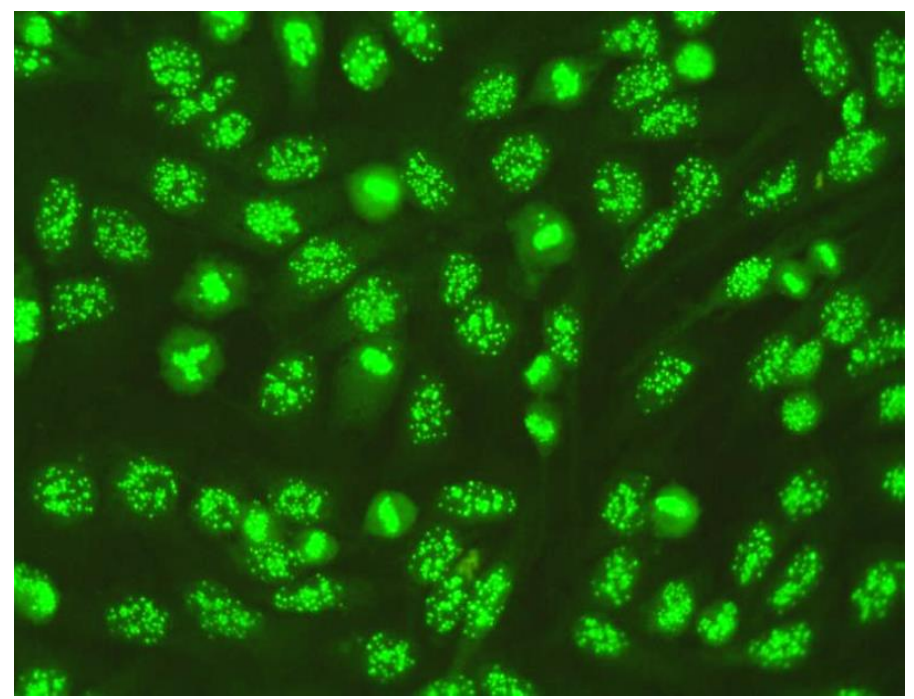

Figure 2. Anticentromere pattern (4+) in IIF.

\section{Discussion}

Rheumatoid diseases are multisystem inflammatory diseases related with the development of autoantibodies to several self-antigens. The liver may be one of the organs affected by these diseases (6). ANA molecular targets specific for autoimmune hepatitis (AIH) are not present. A different profile of ANA positivity reminiscent of that found in Systemic Lupus Erythematosus (SLE) has been informed in AIH. However, at least a third of AIH patients positive for ANA do not react with known nuclear targets $(7,8)$. Himoto et al. have investigated clinical characteristics of patients with autoimmune hepatitis seropositive for anticentromere antibody. In the 
study, the scoring system proposed by the International Autoimmune Hepatitis Group was used for diagnosis of AIH. Seropositivity for ACA was evaluated by a discrete speckled pattern on HEp-2 cells by an immunofluorescent method. Seropositivity for ACA was evaluated by a discrete speckled pattern on HEp-2 cells by an immunofluorescent technique. It was informed that eight (17\%) of 47 patients with AIH had ACA. Statistically significant differences in age, sex, onset pattern of the disease, progression to hepatic failure and relapse rate were not present between the ACA-AIH and other-AIH groups. They reported that the frequency of concurrent autoimmune diseases in ACA-AIH was remarkably higher than that in other-AIH groups (9).

Lodh et al. presented case report associated with a 49year-old type 2 diabetes mellitus patient with abdominal pain and black stool for 15 days. They informed that laboratory investigations provided diagnosis of AIH with anticentromere antibodies. The authors reported that screening AIH patients for anticentromere antibody is not obligatory, however, can be regarded, particularly in the presence of disease-related symptomatology for quicker, more reliable diagnosis and optimum management (10).

The Committee for Autoimmune Serology of the International Autoimmune Hepatitis Group (IAIHG) supplied guidelines on testing for autoantibodies associated with AIH. According to the guidelines IIF screening on fresh sections of liver, kidney, and stomach from rodents should be the first line screening and the use of the three tissues enabling concurrent detection of almost all the autoantibodies related to liver disease, namely, against smooth muscle antigen (SMA), ANA, LKM1, AMA, and LC1 (11).

You et al. informed that there have been only two reports in the literature considering investigations associated with anti-centromere antibodies in patients with AIH. The studies have indicated the presence of these antibodies at a low frequency of $3 \%$ in cases of $\mathrm{AIH}$. The authors reported that the frequency of the discrete speckled pattern of ANA (related to ACA) is increased in AIH patients with ACA, supporting the close association between the AIH and SSc in the Japanese population. They emphasized that no certain consequences can be drawn from these findings, and additional and advanced studies are necessary to examine the relationship between ACA and AIH (12). There are a lot of investigations associated with the clinical significance of ACA in literature (13-16).

\section{Conclusion}

Although, our current study is a preliminary research, we reported our experience in order to provide evidence for the detection of various autoantibodies as potential diagnostic or prognostic tests. Well-designed further studies that contain a broad range of patients may contribute to the field.

Ethics Committee Approval: Ethics Committee approval was received for this study from the ethics committee.

Informed Consent: Written informed consent was obtained from patients who participated in this study.

Peer-review: Externally peer-reviewed.

Conflict of Interest: No conflict of interest was declared by the author.

Financial Disclosure: The author declared that this study has received no financial support.

\section{References}

1. Caramaschi P, Tonolli E, Biasi D, Caimmi C, Pieropan S, Dal Forno I, Scambi C, Adami S. Antinuclear autoantibody profile in systemic sclerosis patients who are negative for anticentromere and anti-topoisomerase I specificities. Joint Bone Spine 2015; 82: 209-210.

2. Sánchez-Montalvá $\mathrm{A}$, Fernández-Luque $\mathrm{A}$, Simeón $\mathrm{CP}$, Fonollosa-Plà V, Marín A, Guillén A, Vilardell M. AntiSSA/Ro52 autoantibodies in scleroderma: results of an observational, cross-sectional study. Clin Exp Rheumatol 2014;32: 177-182.

3. Grace M, Varada, Dhanesh E. Digital gangrene associated with anticentromere antibodies. Indian J Dermatol 2014; 59; 195-196.

4. Miyawaki S, Asanuma $\mathrm{H}$, Nishiyama S, Yoshinaga Y. Clinical and serological heterogeneity in patients with anticentromere antibodies. J Rheumatol 2005; 32: 1488-1494.

5. Marie I, Levesque H, Tranvouez JL, François A, Riachi G, Cailleux N, Courtois H. Autoimmune hepatitis and systemic sclerosis: a new overlap syndrome? Rheumatology (Oxford) 2001; 40: 102-106.

6. Kojima H, Uemura M, Sakurai S, Ann T, Ishii Y, Imazu H, Yoshikawa M, Ichijima K, Fukui H. Clinical features of liver disturbance in rheumatoid diseases: Clinicopathological study with special reference to the cause of liver disturbance. $J$ Gastroenterol 2002; 37: 617-625.

7. Manns MP, Lohse AW, Vergani D. Autoimmune hepatitisUpdate 2015. J Hepatol 2015; 62: 100-111.

8. Bogdanos DP, Mieli-Vergani G, Vergani D. Autoantibodies and their antigens in autoimmune hepatitis. Semin Liver Dis 2009; 29: 241-253.

9. Himoto T, Murota M, Yoneyama H, Deguchi A, Kurokochi K, Senda S, Haba R, Watanabe S, Nishioka M, Masaki T. Clinical characteristics of patients with autoimmune hepatitis 
seropositive for anticentromere antibody. Hepatol Res 2010; 40: 786-792.

10. Lodh M, Pradhan D, Parida A. Autoimmune hepatitis with anti-centromere antibodies. Case Reports Immunol 2013; 2013: 742080 .

11. Bogdanos DP, Invernizzi $P$, Mackay IR, Vergani $D$. Autoimmune liver serology: current diagnostic and clinical challenges. World J Gastroenterol 2008; 14: 3374-3387.

12. You BC, Jeong SW, Jang JY, Goo SM, Kim SG, Kim YS, Jeon CH, Jeen YM. Liver cirrhosis due to autoimmune hepatitis combined with systemic sclerosis. Korean $J$ Gastroenterol 2012; 59: 48-52.

13. Onozuka Y, Shibata M, Yonezawa H, Terauti K, Miyachi $\mathrm{K}$, Ueno $\mathrm{Y}$. Clinical significance of anti-centromere antibody and anti-CENP-B antibody in sera of patients with primary biliary cirrhosis. Rinsho Byori 1996; 44: 877-882.

14. Chan HL, Lee YS, Hong HS, Kuo TT. Anticentromere antibodies (ACA): clinical distribution and disease specificity. Clin Exp Dermatol 1994; 19: 298-302.

15. Salliot C, Gottenberg JE, Bengoufa D, Desmoulins F, Miceli-Richard C, Mariette X. Anticentromere antibodies identify patients with Sjögren's syndrome and autoimmune overlap syndrome. J Rheumatol 2007; 34: 2253-2258.

16. Csepregi A, Szodoray P, Zeher M. Do autoantibodies predict autoimmune liver disease in primary Sjögren's syndrome? Data of 180 patients upon a 5 year follow-up. Scand J Immunol 2002; 56: 623-629.
How to cite?

Sener AG, Bugdacı C, Yula E, Afsar I, Tarhan EF, Kaya S. Investigation of liver autoantibodies in anticentromere antibody positive patients: A preliminary research. J Immunol Clin Microbiol 2016; 1(1). 14-17.

DOI: http://dx.doi.org/10.5455/jicm.8.20160529

Submit your next manuscript to the JICM and take full advantage of:

- Convenient online submission,

- Thorough peer review, Fast Response,

- No charges,

- Immediate publication on acceptance,

- Inclusion in Scopemed and High quality indexes,

- Research which is freely available for redistribution of the worldwide literature

To submit your manuscript, click on http://www.jiacm.com

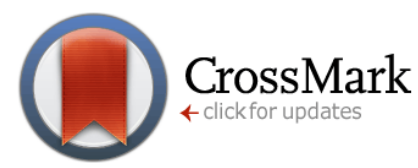

Published by The QMEL.org International Medical Education Library

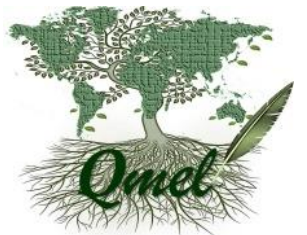

